\title{
Development of a continuous assay for the measurement of tissue factor procoagulant activity on intact cells
}

\author{
Jennifer A Caldwell, Jeffrey G Dickhout, Ali A Al-Hashimi and Richard C Austin
}

Tissue factor (TF) is the major physiological initiator of the coagulation cascade and has an important function in the morbidity and mortality associated with many disease states, including cancer-associated thrombosis and atherosclerosis. TF normally exists in a partially encrypted state and its de-encryption on circulating monocytes, platelets or endothelial cells by inflammatory mediators can lead to thrombosis. Furthermore, many cancer cells express large amounts of TF and these cells communicate readily with the circulation through the fenestrated tumor endothelium. To assess agents or conditions that modulate the encryption state of TF, we developed a continuous assay for the determination of TF procoagulant activity (PCA) in a cell-based system. We have shown the use of this assay at detecting agents that de-encrypt TF thereby leading to an increase in TF PCA in three cancer cell lines, namely, T24/83 bladder carcinoma cells and PC-3 and DU145 prostate cancer cells. Further, through use of this assay, we have shown that the endoplasmic reticulum calcium pump inhibitor, thapsigargin, stimulates the de-encryption of TF. The continuous assay for the determination of TF PCA proved to have inherently less intra- and inter-assay variability than the widely used discontinuous assay and is considerably less labor intensive. Further, the continuous assay produced progress curves that were compatible with curve fitting to allow for the determination of the nature of reaction as well as rate constants for the underlying enzymes, TF/FVIla and FXa. The continuous assay for the assessment of TF PCA on intact cells is applicable for high-throughput screening to allow for the determination of compounds that modulate TF PCA. Laboratory Investigation (2010) 90, 953-962; doi:10.1038/labinvest.2010.59; published online 8 March 2010

KEYWORDS: tissue factor; enzyme kinetics; thrombosis; encryption; chromogenic assay

Tissue factor (TF) is an integral membrane protein considered to be the major physiological initiator of the coagulation cascade. Induction of $\mathrm{TF}$ procoagulant activity (PCA) has direct implications in many diseases that increase the risk of thrombosis, including cancer ${ }^{1}$ and atherosclerosis. ${ }^{2}$ The coagulation cascade has been described as consisting of two pathways that lead to the formation of the fibrin clot: the intrinsic and extrinsic pathways. ${ }^{3}$ The intrinsic clotting pathway is activated by the contact activation of FXII either through the exposure of blood to prosthetic devices or foreign substances. ${ }^{4}$ The extrinsic clotting pathway is initiated by the de-encryption of $\mathrm{TF}$ and the activation of FVII to FVIIa. This description of the coagulation cascade has proven useful in diagnostic tools. However, the division between these pathways does not occur in vivo where clotting is initiated through the action of TF whereas the intrinsic pathway may behave as an important amplifier of the coagulation system. ${ }^{5}$

Cell-surface levels of TF do not directly correlate with TF PCA, suggesting that TF exists on the cell surface in two distinct forms: encrypted (dormant) and de-encrypted (active). ${ }^{6}$ TF encryption provides the cell with a mechanism to elicit a rapid hemostatic response without transcriptional upregulation of the TF gene while minimizing deleterious clot formation. Many agents, including detergents, ${ }^{7} \mathrm{Ca}^{2+}$ ionophores $^{8}$ and oxidants, ${ }^{9}$ can significantly increase TF de-encryption leading to the amplification of TF PCA. Because a large portion of expressed TF is exposed on the cell surface, various regulatory pathways are necessary to maintain TF in an encrypted state to prevent unprovoked

Division of Nephrology, Department of Medicine, St Joseph's Healthcare Hamilton and Hamilton Centre for Kidney Research, McMaster University, Hamilton, ON, Canada

Correspondence: Professor RC Austin, PhD, Division of Nephrology, Department of Medicine, St. Joseph's Healthcare Hamilton and Hamilton Centre for Kidney Research, McMaster University, 50 Charlton Ave. E, Hamilton, ON L8N 4A6, Canada.

E-mail: raustin@thrombosis.hhscr.org

Received 31 August 2009; revised 20 November 2009; accepted 12 January 2010 
widespread coagulation. ${ }^{10}$ There are several proposed mechanisms for regulating cell-surface TF encryption including the formation of TF homodimers, the phospholipid microenvironment (phosphatidylserine exposure), TF compartmentalization in lipid rafts, the endocytosis and degradation of the TF/FVIIa complex and isomerization of the TF disulfide bond. ${ }^{11-13}$ Although several mechanisms of TF post-translational regulation have been proposed, the mode of TF encryption varies between different cell systems. In addition, the mechanisms through which TF is de-encrypted are poorly understood and highly controversial.

In this context, direct measurement of TF protein expression may not accurately represent the thrombogenicity associated with TF due to post-translational modifications that influence TF PCA. ${ }^{14}$ Measuring TF PCA can be achieved by using a two-stage (discontinuous) clotting assay. ${ }^{15-17}$ In this assay, cells are treated for a predetermined period of time with a test agent followed by incubation with a cocktail solution containing FX and FVIIa. After incubation, the reaction is terminated at a set time point and TF PCA is determined by measuring product formation. This two-step clotting assay is the gold standard methodology for measuring TF PCA. However, it is a labor-intensive method limiting the number of samples that can be run simultaneously and uses a single end point determination of product formation occurring during the putative exponential phase of the progress curve. This approach allows for variations in reaction time occurring during the first stage to produce wide variability in product output in the second stage. Further, the arbitrary assignment of the test agent's incubation time in the first stage, especially if the effects of the agent on TF PCA are unknown, makes the assay prone to false-negative results if used as a screening tool.

In this report, we propose a modified version of this gold standard assay: the continuous kinetic assay. Thus, we have combined both steps of the discontinuous assay into a singlestep kinetic assay. This technique produces a progress curve of product formation over time where the rate constants of the TF/FVIIa complex and FXa action can be determined. Further, due to its single-step nature the assay is applicable for use in high-throughput screening of test substances with unknown effects or durations of action on TF PCA. In this assay, measuring TF PCA is dependent on a series of cleavages mediated by serine proteases. However, we acknowledge that certain limitations may arise from the introduction of a test agent that can either cleave the chromogenic substrate directly, independent of TF activation, giving a false-positive result, behave as a serine protease inhibitor and therefore interfere with the action of the TF/FVIIa complex or that of FXa on the chromogenic substrate, or result in cell lysis. However, in light of the fact this method is composed of only one step combined with the automative nature of the assay, it can be applied in highthroughput screening format that can be used to determine both activators and inhibitors of TF PCA.

\section{MATERIALS AND METHODS \\ Cell Culture}

The human bladder carcinoma cell line T24/83 was obtained from American Tissue Culture Collection (ATCC) (Rockville, MD, USA) and was cultured in M199 medium supplemented with $10 \%$ fetal bovine serum (FBS), $100 \mu \mathrm{g} / \mathrm{ml}$ penicillin and $100 \mu \mathrm{g} / \mathrm{ml}$ streptomycin. The prostate cancer cell lines, PC-3 and DU145, were obtained from ATCC. PC-3 cells were grown in F-12K medium containing 10\% FBS, $100 \mu \mathrm{g} / \mathrm{ml}$ penicillin and $100 \mu \mathrm{g} / \mathrm{ml}$ streptomycin. DU145 cells were grown in Eagle's minimum essential medium containing $10 \% \mathrm{FBS}, 100 \mu \mathrm{g} / \mathrm{ml}$ penicillin and $100 \mu \mathrm{g} / \mathrm{ml}$ streptomycin. Cells were cultured at $37^{\circ} \mathrm{C}$ in humidified air with $5 \% \mathrm{CO}_{2}$. The 7-aminoactinomycin D (7-AAD) (Beckman Coulter, Fullerton, CA, USA) viability dye was used to determine the percentage of cell survival after treatment with various agonists used in the TF PCA assay according to the manufacturer's instructions.

\section{TF PCA Agonists}

Ionomycin (Sigma-Aldrich, St Louis, MO, USA) was diluted to a final concentration of $1-20 \mu \mathrm{M}$. Ionomycin is a known inducer of TF PCA for the discontinuous assay and was diluted and incubated on cells for $10 \mathrm{~min}$ as well as used in the continuous assay. Hydrogen peroxide (Sigma-Aldrich) was diluted to a final concentration of $1-20 \mathrm{mM}$ and incubated on the cells for $1 \mathrm{~h}$ in the discontinuous assay and also used in the continuous assay. Thapsigargin (SigmaAldrich) was diluted to a final concentration of $1-20 \mu \mathrm{M}$ and determine by the continuous assay to increase TF PCA. The nonionic detergent Triton X-100 $(0.01 \% \mathrm{v} / \mathrm{v})$ was also used as a TF PCA agonist in the continuous assay for curve fitting experiments.

\section{Discontinuous TF PCA Assay}

Cell-surface TF PCA was measured using the chromogenic reporter substrate S-2765, as described previously by Watson et al. ${ }^{15}$ Briefly, cells were seeded into a 24 -well plate and upon reaching confluence washed in $1 \times$ Tris-buffered saline (TBS). Treatment times and concentrations varied according to the reagent used; however, all treatments were diluted in cell culture media lacking FBS and antibiotics. The plates were maintained at $37^{\circ} \mathrm{C}$ and a cocktail containing $0.5 \mathrm{nM}$ of FVIIa (Enzyme Research Laboratories, South Bend, IN, USA) and $15 \mathrm{nM}$ of FX (Enzyme Research Laboratories) in $1 \times$ TBS was added to each well to a final volume of $304 \mu \mathrm{l}$. At timed intervals, $15 \mu \mathrm{l}$ of $100 \mathrm{mM} \mathrm{CaCl} 2$ was added to each well and allowed to incubate for $30 \mathrm{~min}$. After incubation, $250 \mu \mathrm{l}$ of the reacting solution was transferred to a 96-well plate containing $25 \mu \mathrm{l}$ of $0.2 \mathrm{mM} \mathrm{S}-2765$ (Chromogenix, Lexington, MA, USA) and incubated for $3 \mathrm{~min}$. The reaction was terminated with $20 \mu \mathrm{l}$ of $50 \%$ acetic acid. The absorbance at $405 \mathrm{~nm}$ was determined using a spectrophotometer (Spectromax PLUS) and SOFTmax Pro software (Molecular Device, Sunnyvale, CA, USA). A standard curve was generated 
where $100 \mathrm{U}$ of $\mathrm{TF}$ activity was defined as the amount of activity in $3 \mu$ l of purified rabbit brain thromboplastin (Dade Behring, Deerfield, IL, USA), which is equivalent to $900 \mu \mathrm{g}$ of $\mathrm{TF}$ (as determined by the American Diagnostica ELISA, Stamford, CT, USA). Each well was lysed with RIPA buffer $(0.1 \%$ SDS). Total protein was calculated using the DC Protein Assay (Bio-Rad, Richmond, CA, USA) according to the manufacturer's instructions and described below. Cell-surface TF PCA was calculated as the amount of FXa generated per $\mu \mathrm{g}$ of total cell protein $(\mathrm{U} / \mu \mathrm{g})$.

\section{Continuous TF PCA Assay}

The chromogenic reporter substrate S-2765 was used to measure factor Xa generation as an indirect way of assaying cell-surface TF PCA. An equivalent number of cells were seeded into a 96-well plate and upon reaching confluency $\left(1 \times 10^{4}\right.$ cells per well) rinsed once with $1 \times$ TBS before analysis. Cocktail $(90 \mu \mathrm{l})$ containing $1 \mathrm{nM}$ of FVIIa (Enzyme Research Laboratories), $30 \mathrm{nM}$ of FX (Enzyme Research Laboratories), $10 \mathrm{mM} \mathrm{CaCl} 2$ and $0.4 \mathrm{nM}$ of S-2765 in TBS was added to each well. Each testing agent was diluted in TBS, and the given dose was added by a $10 \mu$ l addition to each well in eight replicates. The absorbance at $405 \mathrm{~nm}$ was then measured kinetically every $2 \mathrm{~min}$ for $3 \mathrm{~h}$ at $37^{\circ} \mathrm{C}$. Maximum kinetic rate $(\mathrm{Vmax})$ was calculated in each well using SOFTmax Pro and compared against the standard curve to determine TF PCA. The standard curve was generated where $100 \mathrm{U}$ of TF activity was defined as the amount of activity in $1.5 \mu$ l of purified human recombiplastin (Dade Behring), which is equivalent to $450 \mu \mathrm{g}$ of TF (as determined by the American Diagnostica ELISA). Cell-surface TF PCA was calculated as the amount of FXa generated per $1 \times 10^{4}$ cells ( $\mathrm{U}$ per $1 \times 10^{4}$ cells). To assess the specificity of the assay for TF, the rabbit anti-human TF antibody (American Diagnostica, \#4502) was used as an inhibitory antibody over a concentration range of $0-10 \mu \mathrm{g} / \mathrm{ml}$ while a rabbit anti-green fluorescent protein (GFP) antibody $(10 \mu \mathrm{g} / \mathrm{ml})$ (Affinity BioReagents, Rockford, IL, USA, \#PA1-980) was used as a nonspecific antibody control.

\section{Quantitation of Total Cellular Protein}

To determine the amount of protein in each test well of the discontinuous assay, we performed the DC Protein Assay (Bio-Rad) in triplicate. Lysates in RIPA buffer were passed through a 21 1/2; gauge needle and centrifuged at 10000 r.p.m. for $2 \mathrm{~min}$. Triplicate aliquots of $5 \mu \mathrm{l}$ of lysates were each incubated with $24.5 \mu \mathrm{l}$ of Reagent A, $0.5 \mu \mathrm{l}$ of Reagent $\mathrm{S}$ and $200 \mu \mathrm{l}$ of Reagent B in a 96-well plate for $15-30 \mathrm{~min}$. The reference standard used in this procedure was a dilution series of Bio-Rad Protein Assay Standard II. Absorbance was measured at $750 \mathrm{~nm}$ on a spectrophotometer using SOFTmax Pro.

\section{Immunoblot Analysis}

Total protein lysates were prepared using $4 \times$ Laemmli sample buffer (50 mM Tris (pH 6.8), 2\% SDS, 10\% glycerol,
$0.01 \%$ bromophenol blue and $50 \mathrm{mM}$ DTT). Lysates were boiled for $5 \mathrm{~min}$ before separation by electrophoresis under reducing conditions on a $10 \%$ SDS-polyacrylamide gel. Proteins were transferred onto a nitrocellulose membrane (Bio-Rad) using the Trans-Blot Semi-Dry transfer apparatus (Bio-Rad). Membranes were blocked overnight in 5\% milk (from powder) in $1 \times$ TBST followed by incubation with the primary rabbit anti-human TF antibody then horseradish peroxidase-conjugated secondary antibodies (Upstate Biotechnology, Lake Placid, NY, USA) diluted in $1 \%$ milk (from powder) in $1 \times$ TBST. Membranes were visualized using the Western Lighting Chemiluminescence Reagent (PerkinElmer, Boston, MA, USA) and Kodak X-OMAT Blue XB-1 film (PerkinElmer) was exposed and developed using a Kodak X-OMAT 1000A Processor. To control for protein loading, immunoblots were re-probed with a mouse monoclonal anti$\beta$-actin antibody (Sigma-Aldrich) after re-blocking overnight in 5\% milk (from powder) in $1 \times$ TBST. All reagents used to make the polyacrylamide gel as well as the electrophoresis apparatus were purchased from Bio-Rad.

\section{Statistical Analysis}

The standard error of the mean for each treatment replicate was established using Excel software (Mississauga, ON, Canada). Significance of differences between control and various treatments was determined by analysis of variance (ANOVA). On finding significance with ANOVA, an unpaired Student's $t$-test was performed. For all analyses, $P \leq 0.05$ was considered significant. To compare the reproducibility of results produced by both the discontinuous and continuous assays, we calculated the intra- and interassay coefficient of variation (CV) for both the discontinuous and continuous assay determinations of TF PCA using the methodology described by Grotjan and Keel. ${ }^{18}$ Further, to determine the predicted nature of the enzymatic reaction with progress curves obtained from the continuous assay, we performed enzymatic kinetic curve fitting using Table Curve 2D software version 5.01 (Systat Software Inc.), where 58 total kinetics equations were fit and best fit was determined by maximizing the $R^{2}$ value.

\section{RESULTS \\ Comparison of Discontinuous vs Continuous Measurement of TF PCA}

Schematic diagrams of the procedure for the discontinuous and continuous FXa generation assays are described in Figure 1a. To determine if the continuous assay developed to measure TF PCA was able to measure increases in TF PCA produced by the known TF agonists ionomycin and hydrogen peroxide, we examined and compared dose responses of these substances to the discontinuous assay system. As previously reported ${ }^{15}$ the discontinuous assay showed a significant increase in TF PCA due to treatment of T24/83 cells with the agonists ionomycin $(1-20 \mu \mathrm{M})$ or hydrogen peroxide 
a

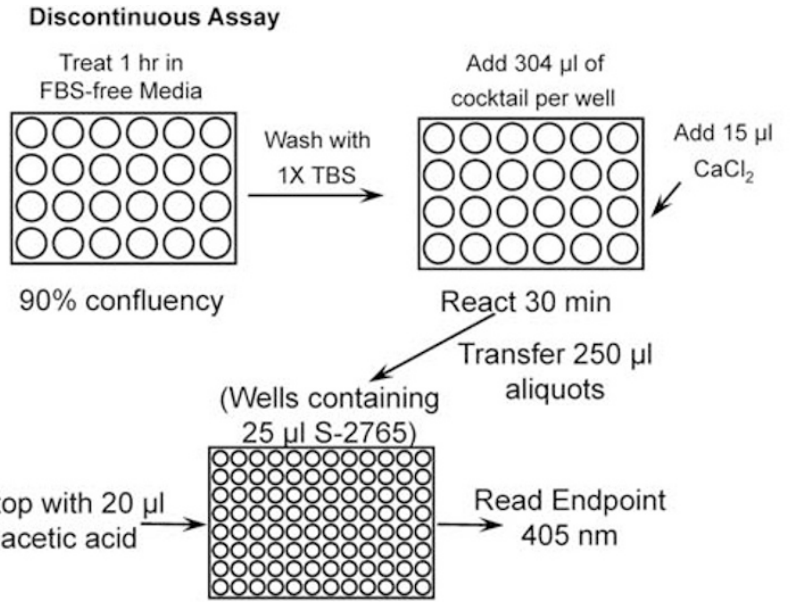

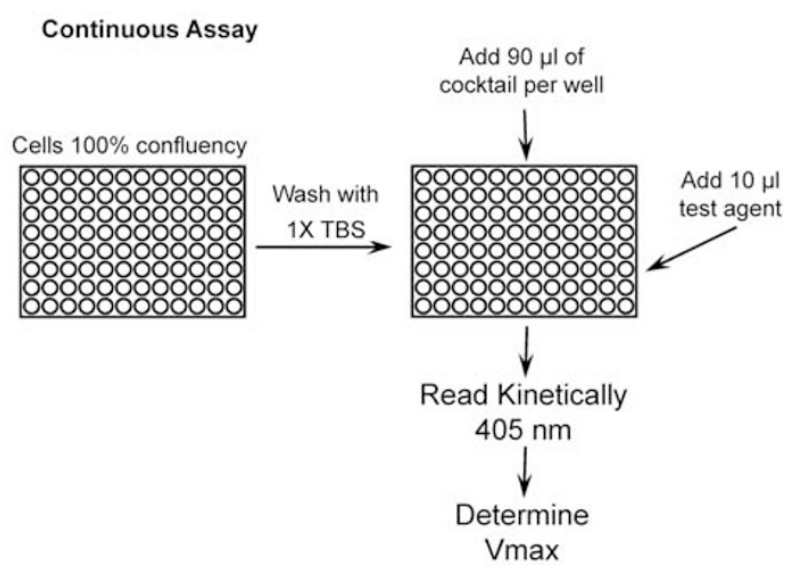
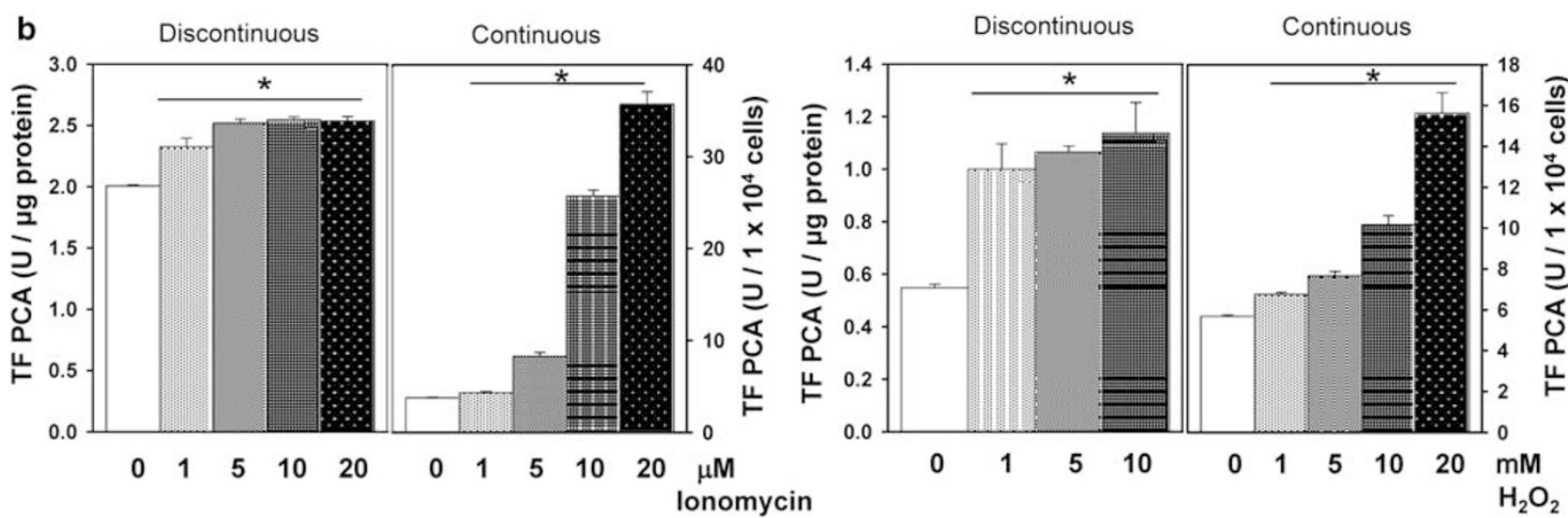

Figure 1 Continuous vs discontinuous measurement of TF PCA. (a) Schematic diagram of the procedure for the discontinuous and continuous FXa generation assays. (b) TF PCA measured both discontinuously and continuously on T24/83 cells in response to the agonists, ionomycin (1-20 $\mu \mathrm{M})$ or hydrogen peroxide $(1-20 \mathrm{mM}) .{ }^{\star} P<0.05$ vs vehicle control.

(1-20 mM). The continuous assay was also able to detect the dose-dependent increase in TF PCA produced in T24/83 cells in response to these agonists (Figure 1b).

\section{Specificity of the Continuous Assay for the Measurement of TF PCA}

To determine if the response measured in the continuous TF PCA assay was specific for TF activation, we used an inhibitory anti-TF antibody to determine if the assay response could be abolished (Figure 2). A nonspecific anti-GFP antibody was used as its control. Progress curves are shown in Figure 2a for the product of FXa's cleavage of the chromogenic substrate, $p$-nitroanilide (pNA), due to stimulation with the endoplasmic reticulum (ER) calcium-releasing substance thapsigargin, drug vehicle control, as well as thapsigargin treatment combined with preincubation of the cells with the anti-TF inhibitory antibody or the nonspecific anti-GFP antibody. Thapsigargin treatment increased TF PCA in T24/83 cells over vehicle control; however, this effect was abolished by preincubation with the anti-TF inhibitory antibody. The nonspecific anti-GFP antibody produced little inhibition of the thapsigargin response. To determine if the Vmax responses to the agonists thapsigargin and ionomycin were specific for TF, preincubation with the anti-TF antibody or the anti-GFP control were used. Both thapsigargin and ionomycin significantly increased the response in Vmax over vehicle control; however, this was significantly inhibited by the anti-TF antibody. The anti-GFP antibody had no significant effect on Vmax (Figure 2b). The fitting of Vmax to standards of purified human recombiplastin allowed the determination of TF PCA ( $\mathrm{U}$ per $1 \times 10^{4}$ cells) generated by ionomycin $(10 \mu \mathrm{M})$, hydrogen peroxide $(10 \mathrm{mM})$ and thapsigargin $(10 \mu \mathrm{M})$. These were all found to be dose dependently inhibited by increasing the concentration of the antiTF inhibitory antibody $(0-10 \mu \mathrm{g} / \mathrm{ml})$ (Figure $2 \mathrm{c}$ ). Further, the assay was performed with the stepwise removal of critical components of the cocktail mix, namely, calcium, chromogenic substrate (S-2765), FX, FVIIa or the cells where ionomycin $(10 \mu \mathrm{M})$ and thapsigargin $(15 \mu \mathrm{M})$ were used as agonists. The reaction was unable to proceed unless all critical components were present and the agonist had no effect with a complete cocktail in the absence of cells, 
a

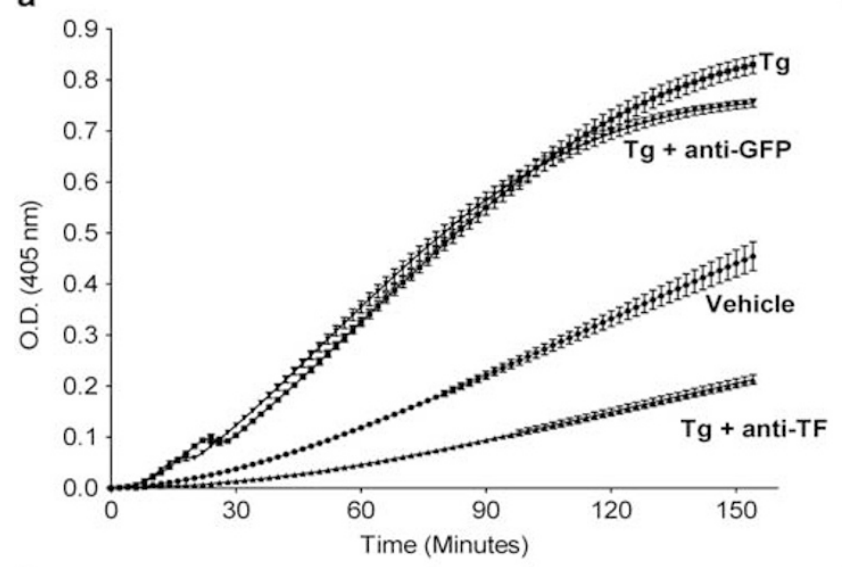

b

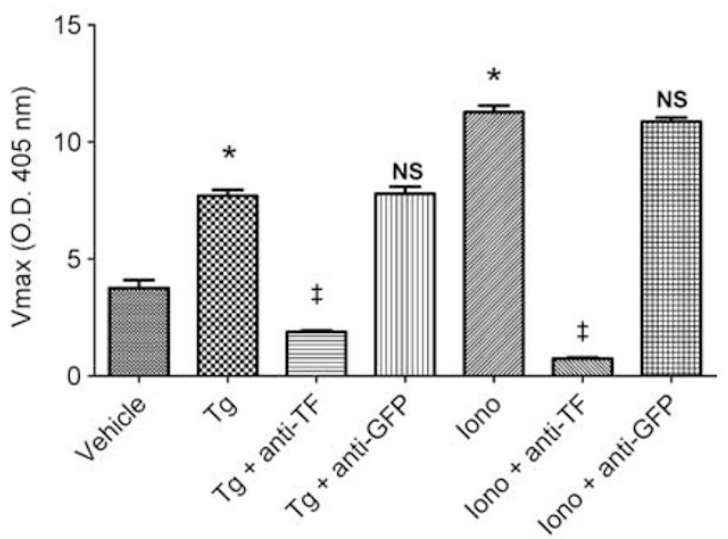

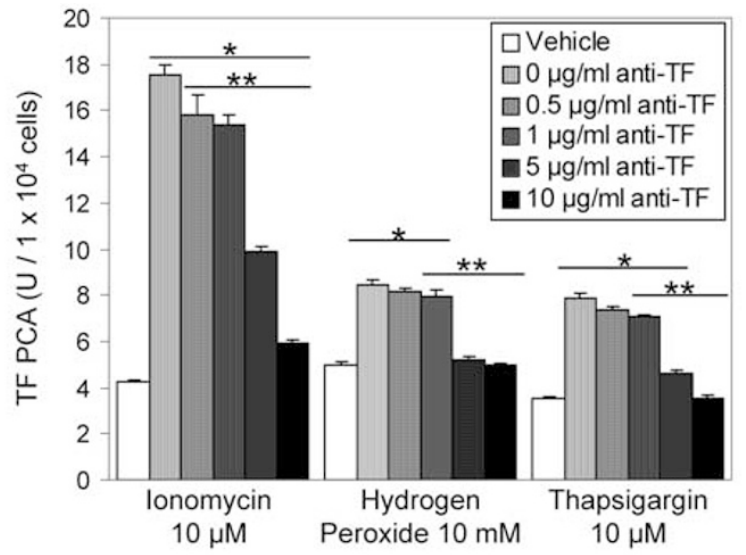

d 25

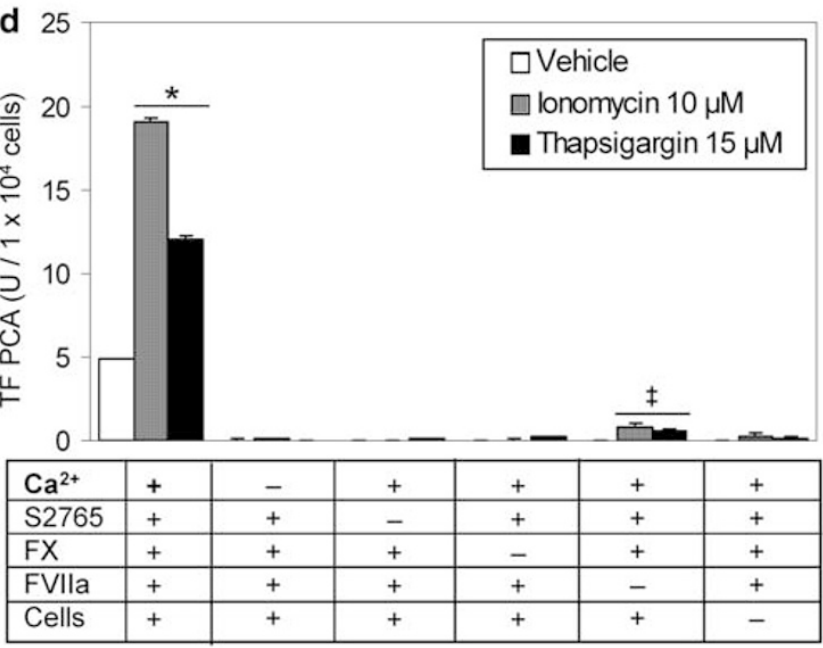

Figure 2 Determination of the specificity of the continuous assay for the measurement of TF PCA. (a) Progress curves for the continuous assay performed on T24/83 cells showing response of vehicle control vs $10 \mu \mathrm{M}$ thapsigargin (Tg), $10 \mu \mathrm{M}$ thapsigargin pretreated with $10 \mu \mathrm{g} / \mathrm{ml}$ anti-TF neutralizing antibody ( Tg + anti-TF) and $10 \mu \mathrm{M}$ thapsigargin pretreated with $10 \mu \mathrm{g} / \mathrm{ml}$ anti-GFP antibody (Tg + anti-GFP) as a control for the specificity of the TF neutralizing antibody effect. (b) Maximum rate of kinetic reaction ( $V \max$ ) derived from progress curves on T24/83 cells showing significant increases in $V m a x$ produced by $10 \mu \mathrm{M} \mathrm{Tg}$ and $10 \mu \mathrm{M}$ ionomycin (iono) treatment $\left({ }^{\star} P<0.05\right.$ vs vehicle control), significant inhibition of this effect by TF neutralizing antibody ( $¥ P<0.05$ vs agonist, Tg and lono) and no significant effect on Vmax of nonspecific antibody control, anti-GFP. (c) TF PCA of T24/83 cells pre-treated with the anti-TF neutralizing antibody (anti-TF, 1-10 $\mu \mathrm{g} / \mathrm{ml})$ followed by treatment with agonist ionomycin $(10 \mu \mathrm{M})$, hydrogen peroxide $(10 \mathrm{mM})$ or thapsigargin $(10 \mu \mathrm{M})$. ${ }^{\star} P<0.05$ vs vehicle control. ${ }^{* *}$ represent significant decrease in agonist response due to pretreatment with anti-TF neutralizing antibody, $P<0.05$. (d) On cell controls using $\mathrm{T} 24 / 83$ cells where each component of the cocktail is absent without stimulation or with ionomycin (10 $\mu \mathrm{M})$ or thapsigargin (15 $\mu \mathrm{M})$ treatment. ${ }^{\star} P<0.05$ vs vehicle control ( $\ddagger$ over 0 ).

indicating that the source of TF PCA increase to be from the test cells (Figure 2d).

\section{Continuous Measurement of TF PCA in Different Cell Lines}

To determine if the continuous assay was able to distinguish different levels of TF PCA between cell lines having different amounts of total TF, we used two prostate cancer cell lines (PC-3 and DU145) in the assay. Western blot analysis was performed to determine the expression of total TF in these cell lines. It was found that T24/83 cells had an intermediate level of total TF protein expression, whereas PC-3 cells had the lowest level and DU145 had the greatest level of expression (Figure 3a). Stimulation of PC-3 and DU145 cells with ionomycin, hydrogen peroxide or thapsigargin showed that both cell lines displayed a dose-dependent increase in TF PCA to these agonists (Figure $3 \mathrm{~b}$ and c). However, TF PCA activity responses in DU145 cells with the greatest amount of TF expression were approximately 50-fold higher than that in PC-3 cells with the lowest amount of TF protein expression. These findings indicate the ability of the continuous assay to distinguish between biologically relevant levels of TF expression in different cell lines.

\section{Agonists Potentially Interfering with the Continuous TF PCA Assay}

In the discontinuous assay, agonists are removed before a determination of TF PCA is made. This allows the assay to be 

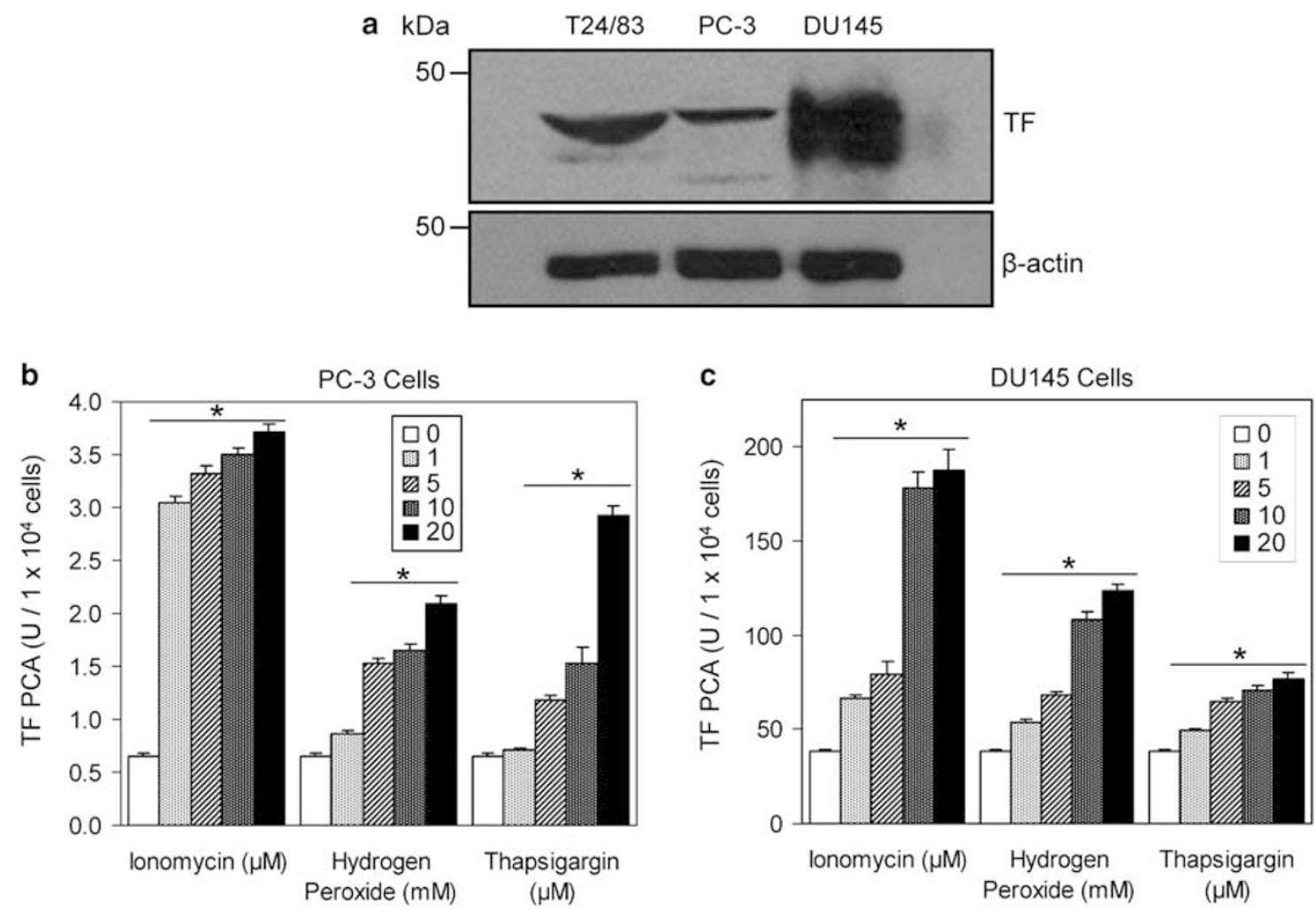

Figure 3 Continuous measurement of TF PCA in cell lines expressing different levels of total TF. (a) Western blot of whole-cell lysates from T24/83, PC-3 and DU145 cells showing levels of TF protein expression. To control for equivalent protein loading, blots were reprobed with anti- $\beta$-actin antibody. Treatment of (b) PC-3 and (c) DU145 cells with ionomycin $(1-20 \mu \mathrm{M})$, hydrogen peroxide $(1-20 \mathrm{mM})$ or thapsigargin $(1-20 \mu \mathrm{M})$. ${ }^{*} P<0.05$ vs vehicle control.

run for only one fixed time point, thereby preventing the generation of kinetic progress curves. However, it does have the advantage of removing test substances that could potentially interfere with the cleavage of $\mathrm{FX}$ and/or the chromogenic substrate. $\alpha_{2}$-Macroglobulin $\left(\alpha_{2} \mathrm{M}\right)$ is a known mobilizer of intracellular calcium through its binding to the cell-surface GRP78 receptor. ${ }^{19}$ However, it is also a broad spectrum proteinase inhibitor capable of inhibiting the serine proteinases found in the continuous TF PCA assay. Use of $\alpha_{2} \mathrm{M}$ as a TF PCA agonist in T24/83 cells in the discontinuous assay showed a dose-dependent increase in TF PCA (Figure 4a). However, the same doses of $\alpha_{2} \mathrm{M}$ in the continuous assay produced no increase in TF PCA whereas thapsigargin did significantly increase TF PCA (Figure 4b). Examination of doses of $\alpha_{2} \mathrm{M}$ on the effect of preactivated FXa's cleavage of the chromogenic substrate S-2765 in a cell-free system showed that $\alpha_{2} \mathrm{M}$ dose dependently inhibited FXa's cleavage of the substrate as shown by a significant reduction in the area under the progress curve response (Figure 4c). These findings indicate that TF PCA agonists that also interfere with TF/FVIIa or FXa enzymatic activity will not be recognized by the continuous assay as opposed to the discontinuous assay system. Agonists resulting in cytotoxicity may also lead to an increase in TF PCA. To show this effect, we used the nonionic detergent Triton X-100 to disrupt the plasma membrane. This resulted in complete cell death after treatment as measured by the 7-AAD viability dye (Figure 4d). Triton X-100 was also shown to increase TF PCA (Figure 5a). However, treatment with agonists that increase TF PCA in the continuous assay system, including thapsigargin $(10 \mu \mathrm{M})$ and ionomycin $(10 \mu \mathrm{M})$ (Figure $5 \mathrm{a})$, did not result in a decrease in cell survival (Figure $4 \mathrm{~d}$ ).

\section{Fitting of Kinetic Equations to Progress Curves}

The ability of the continuous assay to generate progress curves of product formation allows the data generated by this assay to be subjected to further analysis through curve fitting and the determination of the rate constants of the enzymatic reaction. Progress curves for TF PCA agonists of widely varying modes of action, including the SERCA calcium pump inhibitor thapsigargin, calcium ionophore ionomycin and nonionic detergent Triton $X$ are shown in Figure 5a. The maximum rate of product formation (Vmax) for each agonist was then fit to the standard curves of TF PCA produced by known units of recombinant TF which allowed the determination of TF PCA for each substance in T24/83 cells (Figure 5b). Curve fitting to the progress curves shown in Figure $5 \mathrm{a}$ determined the fitted curves shown in Figure $5 \mathrm{c}$. Goodness of curve fit determined by maximum $R^{2}$ value of the fit allowed the selection of the kinetic model of enzymatic 
a

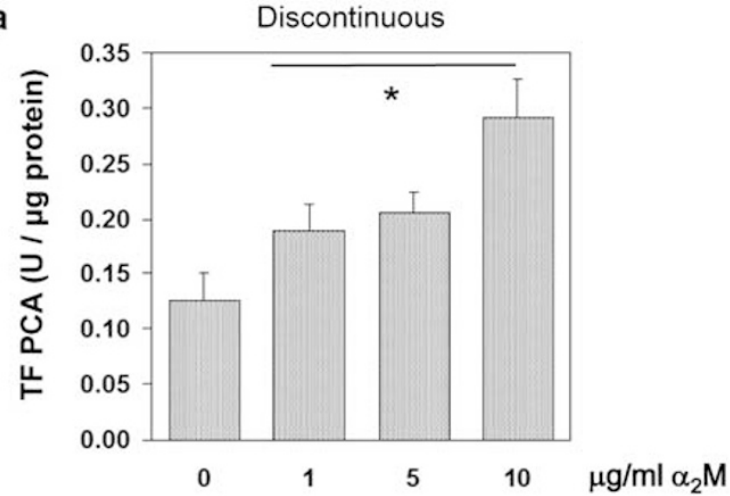

b Continuous
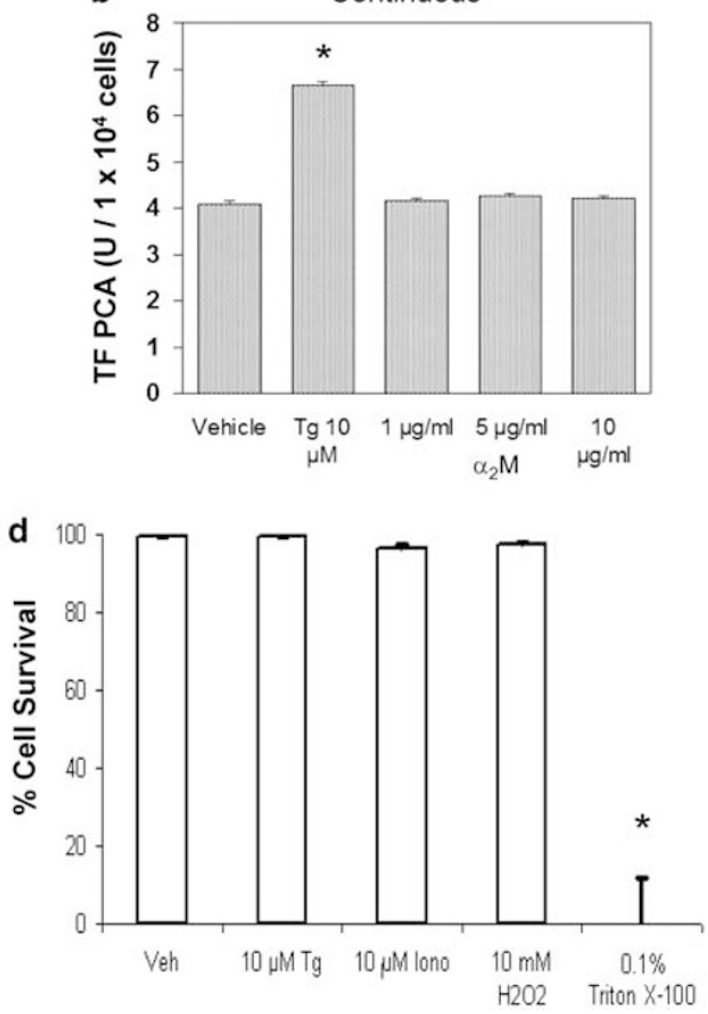

Figure 4 Agonists potentially interfering with the continuous TF PCA assay. (a) The proteinase inhibitor $\alpha_{2}$-macroglobulin $\left(\alpha_{2} \mathrm{M}\right)$ produced a significant increase in TF PCA as measured in the discontinuous assay. ${ }^{\star} P<0.05$ vs vehicle control. (b) $\alpha_{2} \mathrm{M}$ produced no significant response $v s$ vehicle control in the continuous assay, whereas $10 \mu \mathrm{M}$ thapsigargin (Tg) did generate a significant response. ${ }^{\star} P<0.05$ vs vehicle control. (c) Area under the progress curve (AUC) for the continuous assay in cell-free system where FXa was added in the presence of the chromogenic substrate S-2765 and increasing concentration of $\alpha_{2} \mathrm{M}$ produced dose-dependent reduction in the area under the progress curve. ${ }^{\star} P<0.05$ vs vehicle control. (d) Percentage cell survival resulting from treatment with the agonists used in the continuous assay system vs vehicle control. Triton X-100 treatment produced a significant decrease in percentage cell survival as measured by the $7-A A D$ cell viability assay. ${ }^{\star} P<0.05$ vs vehicle control.

product formation that best described the progress curves in Figure 5a. Despite the widely varying modes of activity of the agonists tested, all test substances accurately allowed the prediction of the mode of product formation in the continuous assay as first-order sequential formation (Figure 5d). Where two enzymes, TF/FVIIa complex and FXa lead to the sequential formation of the product, pNA, from the chromogenic substrate allowing for the determination of first-order rate constants $k_{1}$ (TF/FVIIa rate) and $k_{2}$ (FXa rate) from the equation of the fitted curve (Equation (1)).

$$
y=a\left(1+\frac{k_{1}^{\left(-k_{2} x\right)}-k_{2}^{\left(-k_{1} x\right)}}{k_{2}-k_{1}}\right)
$$

The first-order rate constants determined for the drug vehicle $\left(k_{1}=0.011134, \quad k_{2}=0.011103\right), \quad 10 \mu \mathrm{M}$ thapsigargin $\left(k_{1}=\right.$ $\left.0.023933, k_{2}=0.023885\right), 10 \mu \mathrm{M}$ ionomycin $\left(k_{1}=0.050873\right.$, $\left.k_{2}=0.050867\right)$ and $0.01 \%$ Triton X $\left(k_{1}=0.068506, k_{2}=\right.$ $0.068504)$ are in close agreement with the resultant TF PCA calculated from standard curves and show that the rate of TF/FVIIa formation closely determines the rate of FXa through the sequential formation of FXa as product of the first enzymatic reaction.

\section{Reproducibility of the Discontinuous and Continuous Assays}

To assess the reproducibility of both the discontinuous and continuous assays for the determination of TF PCA, we ran the assays both in a cell-free system where known amounts of TF were added to the reaction mixture and in a cell-based assay where the known agonist $10 \mu \mathrm{M}$ ionomycin was used to stimulate a response in T24/83 cells. Replication of these assays within the plate as well as multiple assay runs over many plates with the same agonists allowed the calculation of both the intra- and inter-assay CV for the discontinuous and continuous assays. It was found that in a cell-free system as well as in the cell-based system both the intra- and inter-CV were dramatically lower for the continuous assay (Table 1). 

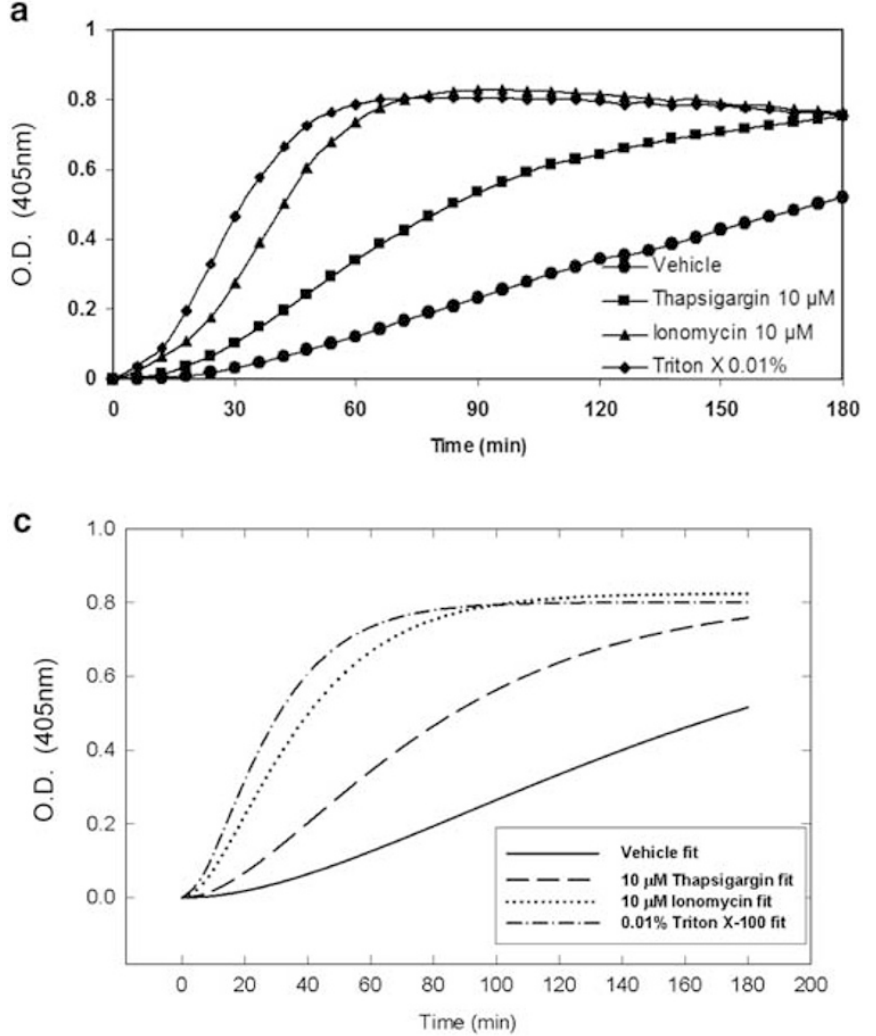

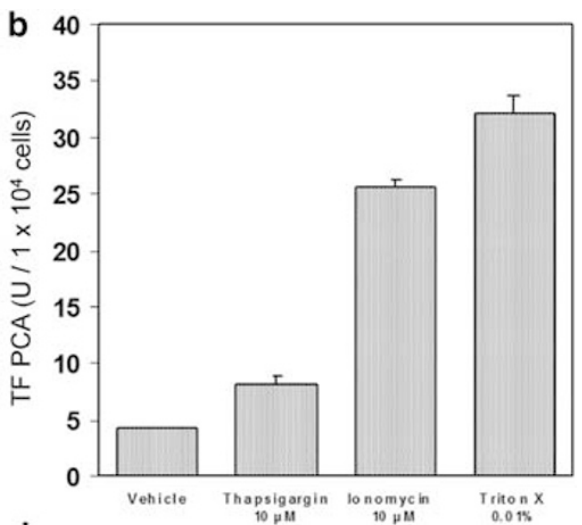

d

First Order Sequential Formation

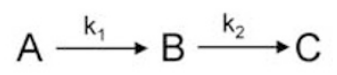

$k_{1}$

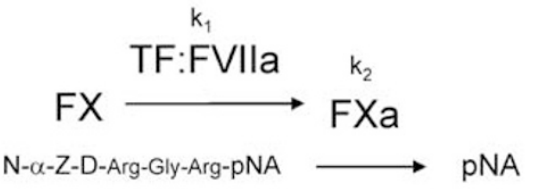

Figure 5 Fitting of progress curves generated by the continuous assay to kinetic equations for product formation to determine form and rate constants of the reaction. (a) Raw progress curve produced by the continuous assay in response to different agonists, thapsigargin $(10 \mu \mathrm{M})$, ionomycin $(10 \mu \mathrm{M})$ or Triton $\mathrm{X}-100(0.01 \% \mathrm{v} / \mathrm{v})$ known to increase TF PCA. (b) TF PCA determined from the progress curves of known agonists by fitting maximum rate of product production (Vmax) to maximum rates produced (Vmax) of known units (U) of recombinant TF. (c) Best curve fits of enzymatic kinetic equations as determined by maximum $R^{2}$ to progress curves shown in $\mathbf{a}$. (d) Nature of reaction determined by curve fitting to the agonists thapsigargin, ionomycin and Triton X-100, first-order sequential formation, with concomitant rate constant determinations, $k_{1}$ and $k_{2}$, by curve fitting in c. Nature determined by progress curve fitting correctly predicted known reaction nature, first-order sequential formation with two enzyme complexes, TF/FVIla and FXa leading to chromogenic product formation, pNA.

Table 1 Comparison of the intra- and inter-assay CV in discontinuous and continuous tissue factor procoagulant activity assays

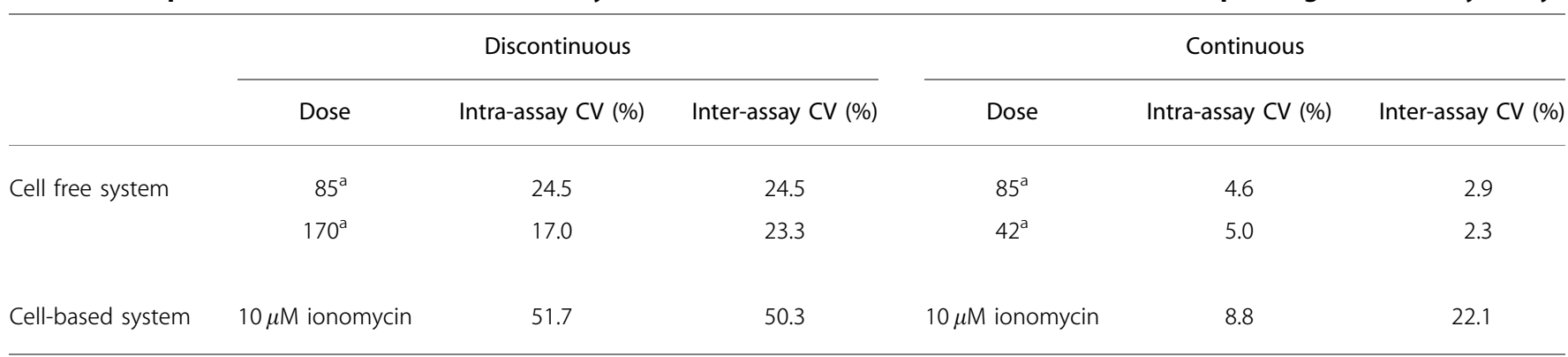

a Tissue factor $(\mu \mathrm{g})$ added to cell-free system.

\section{DISCUSSION}

This study shows the use of a continuous assay for the measurement of TF PCA in a cell-based system. The previously used discontinuous assay, although able to identify agonists of TF PCA, suffers from a greater intra- and interassay variability. This was likely due to the requirement to determine TF PCA from a single end point determination at an arbitrarily determined time. Small differences in the time run during the first step of the discontinuous assay may have resulted in large differences in product formation in the second step due to the steep exponential rate of TF/FVIIa formation induced by many agonists in the first step. In 
contrast, the continuous assay does not rely on a single end point determination of product formation. Instead, determination of the Vmax over the time course of the assay is used that appears to be inherently less subjective to random error variability. Further, the generation of progress curves in the continuous assay, unobtainable in the discontinuous measurement, allowed the application of curve fitting to accurately determine the nature of the reaction understudy, independent of the agonist used, as well as determining the rate constants for the two enzyme components of the assay, namely TF/FVIIa and FXa. It should be noted, however, inter-assay variability of $22 \%$ was observed in the continuous assay (Table 1). This effect may have arisen due to the variable expression of TF in the T24/83 cells used in the inter-assay variability calculation over time in the cell culture environment because inter-assay variability in the cell-free system for the continuous assay was in the $2-3 \%$ range (Table 1).

Indeed, the continuous assay was very sensitive to changes in TF expression in different cell types. This is indicated by the ability of the continuous assay to accurately determine in magnitude the TF PCA responses of the cell lines PC-3 and DU145 that possess widely varying amounts of total TF. Inter-assay variability is the main form of error confounding the comparison of inter-group data from different cell types over time. The continuous assay for the measurement of TF PCA has been used to compare the change in TF PCA produced by HeLa cells over time in culture. It was found that increase in cell density of HeLa cells reduced the units of TF generation per cell. ${ }^{20}$ This effect may contribute to the interassay variability we observed in the continuous TF PCA assay in the cell-based system.

The assay described in this paper appears to be first conceptually established by Carson ${ }^{21}$ based on earlier work by Kosow et $a l^{22}$ with FX activation by Russel's viper venom. Carson showed progress curves produced from the addition of TF to a single-step assay containing a cocktail similar to that used in this paper. ${ }^{21}$ The assay was further established in a cell-based system using HeLa cells to show the substantial differences in TF PCA of nondisrupted $v s$ disrupted cells, ${ }^{20}$ contributing to the concept that TF encryption/de-encryption is an important factor in mediating its biological effect on coagulation. The assay was further used to show detergent induced increases in TF PCA on cultured fibroblasts thereby indicating a function for phospholipid asymmetry in the regulation of TF PCA. ${ }^{7}$

TF encryption/de-encryption appears to be an important point in the coagulation cascade to interfere with the pathological consequences of thrombosis. Increases in cytosolic calcium are believed to result in TF de-encryption through a mechanism involving phospholipid asymmetry. ${ }^{23}$ Indeed we have shown using the continuous assay that a calcium ionophore, ionomycin, increases TF PCA similarly to results shown by Carson and Bromberg. ${ }^{24}$ Further, we have shown in the continuous assay that the ER calcium pump inhibitor, thapsigargin, increases TF PCA in a dose-dependent manner in a variety of cell types that include T24/83, PC-3 and DU145. This effect appeared to be specific for TF activation because it was inhibited by the anti-TF antibody, but not by a control anti-GFP antibody, and thapsigargin treatment resulted in no cytotoxic effects.

The continuous TF PCA assay as presented here is applicable for the high-throughput screen of agents that lead to the de-encryption of TF. It should be noted, however, that unknown agents might have differing effects in the discontinuous $v s$ the continuous TF PCA assay systems. As we have reported, $\alpha_{2} \mathrm{M}$ previously showed to mobilize intracellular calcium, ${ }^{19}$ increases TF PCA in the discontinuous assay system whereas in the continuous system it had no effect. This discrepancy in results appears to be due to $\alpha_{2} \mathrm{M}$ effect as a serine proteinase inhibitor, because we have shown that $\alpha_{2} \mathrm{M}$ dose dependently inhibits the cleavage of the chromogenic substrate by activated FX. It is tempting to speculate which assay system more accurately reflects the physiological action of $\alpha_{2} \mathrm{M}$ on coagulation. Because the continuous assay combines all relevant components of the system simultaneously, unlike the discontinuous system, the continuous system seems to more accurately reflect the physiological system. In this context, it should be noted that $\alpha_{2} \mathrm{M}$ functions as a blood coagulation inhibitor. ${ }^{25}$

In conclusion, we describe a continuous assay for the measurement of TF PCA that shows less intra- and interassay variability than the commonly used discontinuous assay we as well as others have used previously. ${ }^{15}$ This assay has the advantage of being applicable to the screening of large numbers of compounds for the induction of TF PCA as well as inhibitors of TF PCA stimulated by our test substance thapsigargin, ionomycin or hydrogen peroxide. The state of TF encryption/de-encryption measured by this assay appears to be a critical factor in determining the pathological consequences of unregulated thrombosis observed in many disease states, including cancer-related thrombosis and atherosclerosis. In this context, the continuous assay system offers promise for the elucidation of agents/conditions that may interfere with the de-encryption of TF and thus reduce the morbidity and mortality associated with the pathological manifestation of thrombotic disease.

\section{ACKNOWLEDGEMENTS}

This work was supported in part by research grants to Richard Austin from the Heart and Stroke Foundation of Ontario (T-6146), the Canadian Institutes of Health Research (MOP-74477) and the Ontario Research and Development Challenge Fund. Financial support from St Joseph's Healthcare Hamilton and a CIHR Team Grant in Thromboembolism (FRN-79846) is acknowledged. Jeffrey G. Dickhout was supported by the St Joseph's Healthcare Hamilton Division of Nephrology Junior Research Award. Richard C. Austin is a Career Investigator of the Heart and Stroke Foundation of Ontario and holds the Amgen Canada Research Chair in the Division of Nephrology at St Joseph's Healthcare and McMaster University.

\section{DISCLOSURE/CONFLICT OF INTEREST}

The authors declare no conflict of interest. 
1. Carson SD, Brozna JP. The role of tissue factor in the production of thrombin. Blood Coagul Fibrinolysis 1993;4:281-292.

2. van der Wal AC, $\mathrm{Li} X$, de Boer OJ. Tissue factor expression in the morphologic spectrum of vulnerable atherosclerotic plaques. Semin Thromb Hemost 2006;32:40-47.

3. Berg JM, Tymoczko JL, Stryer L. Biochemistry, 5th edn. WH Freeman and Company: New York, 2002.

4. Gailani D, Renne T. Intrinsic pathway of coagulation and arterial thrombosis. Arterioscler Thromb Vasc Biol 2007:27:2507-2513.

5. Rock G, Wells P. New concepts in coagulation. Crit Rev Clin Lab Sci 1997;34:475-501.

6. Bach R, Rifkin DB. Expression of tissue factor procoagulant activity: regulation by cytosolic calcium. Proc Natl Acad Sci USA 1990;87: 6995-6999.

7. Carson SD. Manifestation of cryptic fibroblast tissue factor occurs at detergent concentrations which dissolve the plasma membrane. Blood Coagul Fibrinolysis 1996;7:303-313.

8. Bach RR, Moldow CF. Mechanism of tissue factor activation on $\mathrm{HL}-60$ cells. Blood 1997;89:3270-3276.

9. Penn MS, Cui MZ, Winokur AL, et al. Smooth muscle cell surface tissue factor pathway activation by oxidized low-density lipoprotein requires cellular lipid peroxidation. Blood 2000;96:3056-3063.

10. Drake TA, Ruf W, Morrissey JH, et al. Functional tissue factor is entirely cell surface expressed on lipopolysaccharide-stimulated human blood monocytes and a constitutively tissue factor-producing neoplastic cell line. J Cell Biol 1989;109:389-395.

11. Kunzelmann-Marche C, Satta N, Toti F, et al. The influence exerted by a restricted phospholipid microenvironment on the expression of tissue factor activity at the cell plasma membrane surface. Thromb Haemost 2000;83:282-289.

12. lakhiaev A, Pendurthi UR, Voigt J, et al. Catabolism of factor VIla bound to tissue factor in fibroblasts in the presence and absence of tissue factor pathway inhibitor. J Biol Chem 1999;274:36995-37003.

13. Roy S, Paborsky LR, Vehar GA. Self-association of tissue factor as revealed by chemical crosslinking. J Biol Chem 1991;266: 4665-4668.
14. Egorina EM, Sovershaev MA, Osterud B. Regulation of tissue factor procoagulant activity by post-translational modifications. Thromb Res 2008;122:831-837.

15. Watson LM, Chan AK, Berry LR, et al. Overexpression of the 78-kDa glucose-regulated protein/immunoglobulin-binding protein (GRP78/BiP) inhibits tissue factor procoagulant activity. J Biol Chem 2003;278:17438-17447.

16. Osterud B. Platelet activating factor enhancement of lipopolysaccharide-induced tissue factor activity in monocytes: requirement of platelets and granulocytes. J Leukoc Biol 1992;51:462-465.

17. Sovershaev MA, Egorina EM, Gruber FX, et al. High tissue factorexpressing human monocytes carry low surface CD36: application to intersubject variability. J Thromb Haemost 2007;5:2453-2460.

18. Grotjan $\mathrm{HE}$, Keel BA. Data interpretation and quality control. In: Diamandis EP, Christopoulos TK (eds). Immunoassay, 1st edn. Academic Press: Toronto, 1996.

19. Gonzalez-Gronow M, Cuchacovich M, Llanos C, et al. Prostate cancer cell proliferation in vitro is modulated by antibodies against glucoseregulated protein 78 isolated from patient serum. Cancer Res 2006;66:11424-11431.

20. Carson SD, Archer PG. Tissue factor activity in HeLa cells measured with a continuous chromogenic assay and ELISA reader. Thromb Res 1986;41:185-195.

21. Carson SD. Computerized analysis of enzyme cascade reactions using continuous rate data obtained with an ELISA reader. Comput Programs Biomed 1985;19:151-157.

22. Kosow DP, Furie B, Forastieri H. Activation of factor X: kinetic properties of the reaction. Thromb Res 1974;4:219-227.

23. Bach RR. Tissue factor encryption. Arterioscler Thromb Vasc Biol 2006;26:456-461.

24. Carson SD, Bromberg ME. Tissue factor encryption/de-encryption is not altered in the absence of the cytoplasmic domain. Thromb Haemost 2000;84:657-663.

25. Bikfalvi A, Beress L. Natural proteinase inhibitors: blood coagulation inhibition and evolutionary relationships. Comp Biochem Physiol B 1987;87:435-441. 